\title{
Música para ritual masónico de Ramón Figueroa Morales: Documentos testimoniales sobre la práctica musical en la logia Prudencia no. 2 de Santiago de Cuba (1898-1928)
}

\author{
Música para ritual masónico by Ramón Figueroa Morales: \\ Testimonial documents on the musical practice in the Lodge \\ Prudencia no. 2 in Santiago de Cuba (1898-1928)
}

\author{
Pablo Alejandro Suárez Marrero \\ Universidad de Guanajuato, México \\ pdpablosuarez@gmail.com
}

Recepción: 20 de febrero de 2018/ Aceptación: 9 de abril de 2018.

doi: https://doi.org/10.15517/rehmlac.v10i1.32494

Palabras clave

Música masónica; ritual masónico; Santiago de Cuba; Ramón Figueroa Morales; América Latina.

Keywords

Masonic music; Masonic Ritual; Santiago de Cuba; Ramón Figueroa Morales; Latin America.

Resumen

Hasta hace poco, los estudios sobre las prácticas musicales al interior de una logia masónica cubana eran casi inexistentes. Con la identificación de la Música para ritual masónico de Ramón Figueroa Morales dentro del Archivo de Música de la Catedral de Santiago de Cuba (AMCSC), se dio el primer paso hacia el entendimiento del tema en cuestión, su salvaguarda como posible bien integrante del patrimonio musical nacional y socialización de los resultados en medios especializados. Con conocimientos provenientes de la gestión documental, de la información y del conocimiento, se implementó una propuesta metodológica realizada expresamente para la gestión del patrimonio histórico-documental de la música en Cuba. Con la sistematización de las acciones de localización, identificación, inventario, catalogación, digitalización, estudios aplicados y difusión, aplicadas en su conjunto a los documentos de música anotada abordados, se pudo caracterizar las particularidades músico-funcionales del objeto de estudio y llegar a conclusiones generales al respecto.

\footnotetext{
Abstract

Until recently, studies on musical practices within Cuban Masonic lodges were almost non-existent. Upon the finding of Ramon Figueroa Morales Music for Masonic Ritual within the Music Archive of the Cathedral of Santiago de Cuba (AMCSC), a first step was taken to understand the subject, its safeguard as part of the national musical heritage and the communication of research results in specialized media. Based on document management, information management and knowledge management, a methodological proposal was implemented expressly for the management of the historical-documentary heritage of music in Cuba. With the systematization of location, identification, inventory, cataloging, digitization, applied studies and broadcasting, applied to the annotated music documents addressed, it was possible to characterize the musical-functional particularities of the object of study and reach conclusions about it.
} 


\section{Introducción}

A pesar de que en Cuba las investigaciones sobre la masonería son cuantiosas, mayormente abocadas a constatar su evolución institucional y la biografía de miembros notables, hasta el momento no se habían realizado estudios académicos que desentrañaran el papel de la práctica musical en los rituales masónicos y otras actividades paramasónicas. Va a ser hasta el año 2016 que saldrán a la luz las primeras partituras que dan cuenta documental de dichas prácticas artísticas, así como de la circulación de música y músicos entre diferentes ámbitos sociales en una misma ciudad. De esa forma, se vieron objetualizados los aportes de la Masonería al patrimonio histórico-documental de la música cubana, siendo pertinente su rescate y salvaguarda. Pero ¿dónde se localizó la Música para ritual masónico compuesta por Ramón Figueroa Morales?, ¿cómo identificar dichas partituras dentro de un corpus musical tan heterogéneo?, ¿qué campos descriptivos debía contener el inventario primo y posterior catálogo del compositor estudiado?, ¿cómo digitalizar los documentos sin comprometer su integridad y conservación?, y ¿cuáles estudios realizar sobre tan particular música? Para dar respuesta a cada una de estas preguntas se implementaron las acciones descritas en la "Propuesta metodológica para la gestión del patrimonio históricodocumental de la música", ejecutando los procesos de investigación, protección, conservación y difusión de forma sistémica, cuyo máximo resultado es el presente artículo.

Al aplicar la propuesta metodológica a la gestión de la Música para ritual masónico se consiguió - en primera instancia- validar dicha propuesta desde el punto de vista práctico, y rescatar estos peculiares bienes musicales que -aunque desconocidos - deben formar parte del patrimonio histórico-documental de la música en Cuba. Se tuvo en cuenta que las labores de estudio son transversales a todas las acciones que la integran. Es por ello, que antes de comenzar a aplicar el procedimiento planteado, fue imprescindible la realización de investigaciones preliminares que permitieran contextualizar esta aplicación y entender el objeto de estudio. En aras de comprender a plenitud la Música para ritual masónico, se elaboró una biografía de su compositor que permitió contextualizar su obra creativa y determinar algunas de las influencias musicales obtenidas a lo largo de su vida. De esa misma forma, fue oportuno realizar un análisis músico-funcional de las obras objeto de estudio, para determinar sus características intrínsecas y el lugar que deben ocupar dentro de la liturgia masónica.

Sin la realización de la presente investigación hubiera sido poco posible conocer la relación existente entre masonería y práctica musical dentro de la liturgia masónica en Cuba, la biografía de Ramón Figueroa Morales y su contexto, así como las particularidades músico-funcionales de su Música para ritual masónico. Esto ratifica que para lograr una gestión efectiva de los bienes culturales que integran el patrimonio

\footnotetext{
${ }^{1}$ Pablo Alejandro Suárez Marrero, "Propuesta metodológica para la gestión del patrimonio históricodocumental de la música en Cuba" (Tesis de licenciatura en preservación y gestión del patrimonio histórico-cultural, Universidad de La Habana, 2016).
} 
histórico-documental de la música cubana se debe entender el importante papel que desempeña la investigación en cada una de sus acciones, pues es sumamente difícil rescatar y salvaguardar un patrimonio que no se conoce.

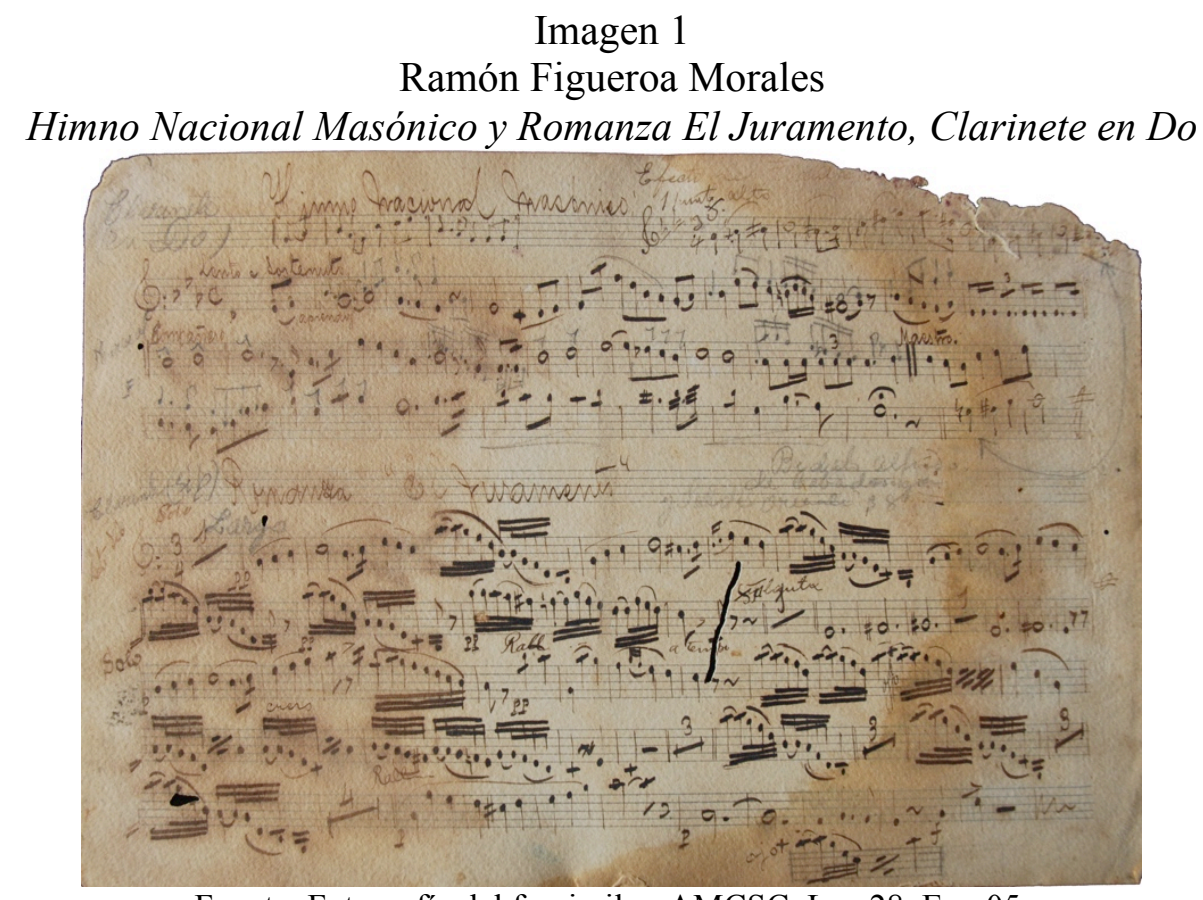

Fuente: Fotografía del facsimilar, AMCSC, Leg.28, Exp.05.

\section{Masonería y música en Cuba (siglo XIX - primeras décadas del XX)}

Según se referencia en la introducción al "Diccionario Enciclopédico Abreviado de la Masonería", la masonería es una institución filantrópica e iniciática que tiene por principios fundamentales la tolerancia mutua, el respeto de sí mismo y de los demás, así como la libertad absoluta de pensamiento y conciencia. La masonería moderna - surgida en Inglaterra a finales del siglo XVII- cambió el carácter de los antiguos gremios de constructores, transformándolas en asociaciones que habían de consagrarse a la lucha por el progreso de sus miembros y la difusión de ideas de avance entre los hombres. De esas organizaciones gremiales actualmente se conservan las denominaciones de las primeras jerarquías, algunos de sus símbolos y gran parte de sus ceremonias. Esta institución fraternal se organiza en logias o talleres que, agrupadas en un mínimo de tres, conforman grandes logias, grandes orientes o supremos consejos, donde se reúnen los masones. Estos se inician en tres grados fundamentales o simbólicos: aprendiz, compañero y maestro; pero, atendiendo al rito al que se afilian las logias, sobre estos han sido creados otros grados de categoría más alta. En el curso de su desenvolvimiento fue inevitable que surgieran numerosas ramificaciones o ritos que difieren en lo relativo al ceremonial y organización, pero que conservan de común los principios de pensamiento y acción fundamentales de la masonería ${ }^{2}$.

\footnotetext{
${ }^{2}$ Lorenzo Frau Abrines, Diccionario Enciclopédico Abreviado de la Masonería (Buenos Aires: Editorial Kiev, 1962), 7-9.
} 
Fue en el período comprendido entre los años 1798-1830 cuando se introdujo e institucionalizó la masonería en Cuba, según consta en "Legados perdurables de la masonería en Cienfuegos (1878-1902)" de Samuel Sánchez. Las primeras logias establecidas en la Isla lo hicieron bajo la influencia del Gran Oriente de Francia y, a partir de 1820, se crearon las condiciones legales para el surgimiento de cuerpos masónicos propios - la Gran Logia del Rito de York y el Gran Oriente Territorial Español Americano del Rito de Escocia- que aglutinarían a las logias existentes en el país. A partir de 1824, con la prohibición de la masonería en España y sus colonias, comenzó en Cuba un declive en el ejercicio masónico, desconociéndose la existencia de alguna logia regular en la Isla entre 1830 y 1857. Es en 1857 que son creadas las logias Fraternidad No. 1 y Prudencia no. 2 en Santiago de Cuba, ambas con Carta Patente de la Gran Logia de Carolina del Sur, Estados Unidos. A estas se sumó, dos años después, la Logia San Andrés no. 3, tríptico que en 1859 constituyó la Gran Logia de Colón. Samuel Sánchez señala que la creación de esta gran logia favoreció el proceso mediante el cual, los masones cubanos ajustaron los principios institucionales a la cultura y realidad de la Isla, forjando su propio ideario y quehacer masónicos ${ }^{3}$.

En 1868, iniciada la Guerra de los Diez Años, la institución masónica y sus miembros sufrieron la represión de las autoridades españolas llegando al caso de que el gran maestro de la Gran Logia de Colón fuera asesinado. Casi una década después, en 1876, se creó la Gran Logia de la Isla de Cuba en La Habana, promovida por Aurelio Almeida González. Para 1888 se fusionaron ambas grandes logias para crear la Gran Logia de Colón e Isla de Cuba y, tras la afiliación a ésta de otras logias cubanas dependientes de grandes orientes hispanos, adoptaría el nombre de Gran Logia de la Isla de Cuba en $1891^{4}$. Transcurrido poco más de un mes de iniciada la Guerra Necesaria en 1895, España prohibió nuevamente el ejercicio de la masonería en Cuba y, salvo muy contadas excepciones, las logias dejaron de funcionar hasta finalizada ésta. Al decir de Samuel Sánchez: "Al asumir los Estados Unidos la administración de Cuba en 1899, la masonería cubana reinició sus labores, reajustó sus proyecciones y trabajos a la nueva realidad y recibió, como nunca antes, una oleada de nuevos miembros",

Consecuentemente con lo que expresa Eduardo Torres-Cuevas en Historia de la masonería en Cuba. Seis ensayos, los albores de la República, a los ojos de los masones, era el hábitat natural de la institución. El trabajo intelectual que realizaron sus miembros entre 1902 y 1930 no ha tenido parangón en toda la historia de Cuba. Tal es el caso que, en el interior de las logias, se debatieron los proyectos que propugnaban los liberales cubanos para la conformación de una sociedad nueva y vieron la luz algunas de las obras intelectuales más importantes de la época ${ }^{6}$. Ejemplo de lo anterior constituye el discurso sobre las transformaciones en la educación superior, realizado por

\footnotetext{
3 Samuel Sánchez Gálvez, Legados perdurables de la masonería en Cienfuegos (1878-1902) (Cienfuegos: Editorial Mecenas, 2010), 20.

${ }^{4}$ Sánchez Gálvez. Legados perdurables, 22-24.

${ }^{5}$ Sánchez Gálvez. Legados perdurables, 24.

${ }^{6}$ Eduardo Torres-Cuevas, Historia de la masonería en Cuba. Seis ensayos (La Habana: Ediciones Imagen Contemporánea, 2013), 220-228.
} 
Enrique José Varona en la sede de la Gran Logia de la Isla de Cuba. A esto se suma que la masonería cubana desarrolló una intensa actividad social durante ese período, permeando la vida cultural del país. Entre los años 1910 y 1933, sus publicaciones en la prensa nacional y el incremento de su propaganda convirtieron a la masonería en cotidiana referencia ${ }^{7}$.

En cuanto al papel de la música en el ritual masónico, el especialista Daniel Beresniak en la versión castellana de su libro "Los oficios y los oficiales de la logia" menciona que "[...] la música es absolutamente indispensable en el ritual, no solamente con ocasión de las ceremonias especiales, sino durante la apertura de los trabajos y durante el ingreso en la logia" ${ }^{\text {. }}$ Su importancia radica esencialmente en que debe apoyar la función de la liturgia masónica: el "descondicionamiento" y "reacondicionamiento" de los iniciados masones hacia un modo diferente de ser. Es por ello que J.D.R.Y. —en su artículo sobre el Himno Masónico Universal- señala que la música ejerce un papel mediador entre lo intelectual y lo espiritual. La música representa el equilibrio y orden, cuyo lenguaje universal tiene la capacidad de provocar emociones". Esta idea había sido esbozada por Daniel López en "Mozart y la Masonería". El gran arquitecto de la música", cuando indica que entre la música y esta institución existe una gran implicación, entendiendo a la música como una de las siete artes liberales que simboliza la armonía del mundo y la que debe existir entre los propios hermanos masones ${ }^{10}$.

J.D.R.Y. referencia que la música en la logia está representada por la columna de armonía o columna armónica - se refiere a un conjunto de músicos instrumentistasdestinada a la ejecución de la música en el transcurso de los rituales ${ }^{11}$. Esta columna en particular, bajo la conducción del maestro de armonía o director de la columna armónica, ha tenido como misión aportar un complemento musical al ritual. Es por eso que L.I.F. en "Algunas apreciaciones sobre la Columna de Armonía” expresa que el oficio de Maestro de Armonía supone que este oficial tenga tanto una cultura musical, como un profundo conocimiento del ritual. La relación entre ambas capacidades le permitiría al maestro desplegar una expresión sonora acorde con cada una de las escenas del psicodrama masónico, subordinado en todo momento al propio rito ${ }^{12}$.

Fue en el siglo XVIII que comenzaron a introducirse instrumentos musicales en las logias, cuyo formato inicial, heredero de las bandas militares de música, estuvo conformado por dos clarinetes, dos fagotes y dos cornos. La conformación y tamaño de las columnas de armonía dependía de la disponibilidad de músicos que integraban la respectiva logia. Sin embargo, a fin de mantenerlas en funcionamiento permanente se

\footnotetext{
${ }^{7}$ Torres-Cuevas. Historia de la masonería, 232.

${ }^{8}$ Daniel Beresniak, Los oficios y los oficiales de la logia (Bogotá: Ediciones Detrad, 2001), 59.

http://davidbenavente123.galeon.com/aficiones1388372.html

${ }^{10}$ Daniel López Figaldo, "Mozart y la Masonería. El gran arquitecto de la música”, Filomúsica. Revista de música culta 41 (junio 2003), http://www.filomusica.com/filo41/mozart.html

${ }^{11}$ J.D.R.Y., "Himno Masónico Universal".

${ }^{12}$ L.I.F. ,Algunas observaciones sobre la Columna de la Armonía (París: Gran Oriente de Francia, 2012).

(2005),
} 
adoptó la costumbre de iniciar músicos, llamados hermanos de la armonía o hermanos artistas. Ellos estaban exentos de pagar cotizaciones reglamentarias a cambio de sus servicios, solo se le limitaba a la obtención de los tres grados simbólicos y, generalmente, no eran promovidos a puestos de oficiales dentro de la institución masónica $^{13}$.

Las dos primeras referencias a la existencia de músicos en la masonería cubana del siglo XIX son las encontradas en el listado de profesiones, ocupaciones y oficios ejercidos por los miembros de la logia cienfueguera Fernandina de Jagua entre 1878 y $1902^{14}$. En dicho documento no se explicitan los nombres de los hermanos artistas, pero coadyuva a conocer su pertenencia a la institución, dejando sentada la posibilidad de futuros estudios que tengan en cuenta este detalle. La música para ritual masónico compuesta por Ramón Figueroa Morales constituye actualmente la única colección de documentos de música anotada conocida que dan cuenta de la práctica musical directamente relacionada a rituales masónico en Cuba en los comienzos del siglo XX. Estas partituras manuscritas son excelentes fuentes primarias de información para intentar reconstruir lo que en materia musical debió realizarse al interior de la logia masónica Prudencia no. 2 de Santiago de Cuba, a la cual perteneció el compositor y de cuya Columna Armónica fue su director.

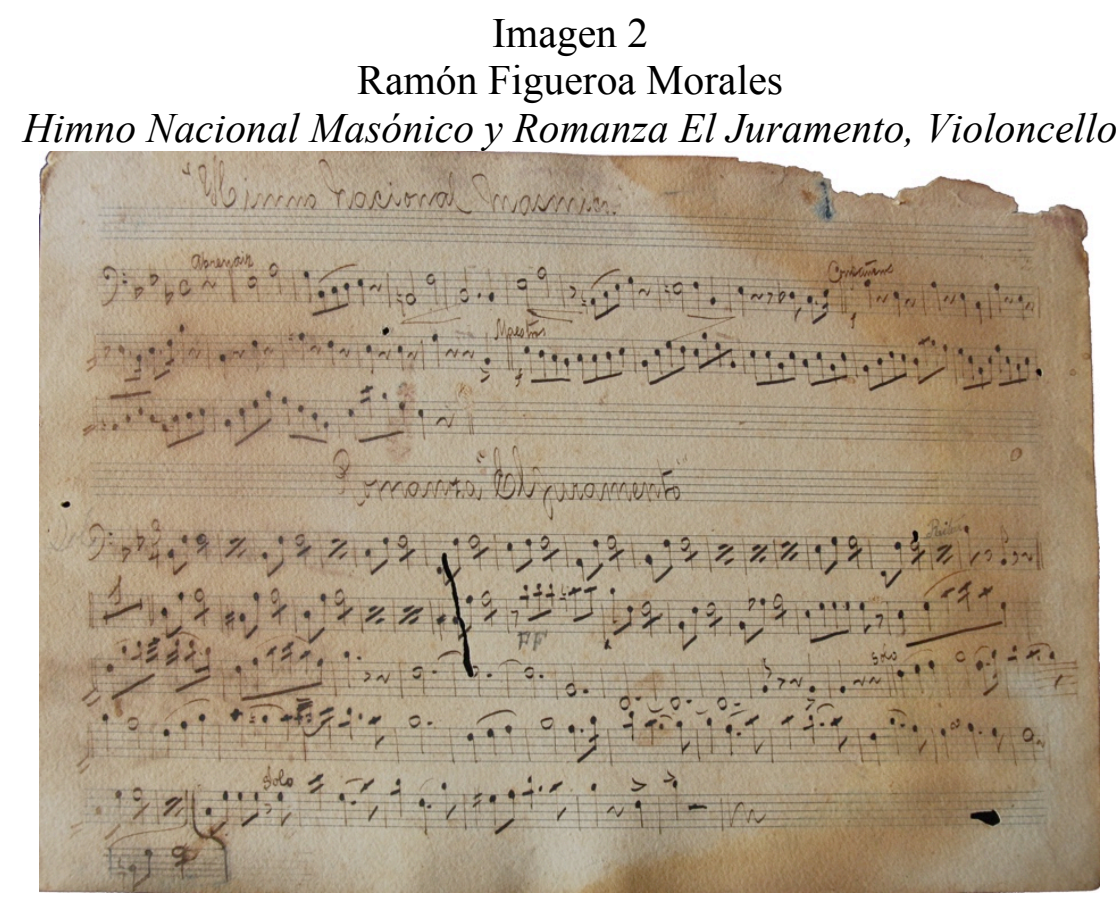

Fuente: Fotografía del facsimilar, AMCSC, Leg.28, Exp.05.

\footnotetext{
${ }^{13}$ Roges Cotte, La Musique Maconnique et Ses Musiciens (Braine-le-Comte: Editions du Baucens, 1975), citado por Juan de Dios López Maya, Columnas de Armonía. La tradición musical masónica del siglo XVIII y su reflejo en las logias venezolanas del siglo XIX (Caracas: s.e., 2012), 7.

${ }^{14}$ Sánchez Gálvez, Legados perdurables, anexo 1.
} 


\section{Localización e Identificación}

Aun cuando por lógica se puede prever que los sitios idóneos para encontrar fuentes documentales relativas a las prácticas musicales masónicas son las mismas logias donde se gestaron, ningún investigador debe desaprovechar las oportunidades que le brinda el azar. La Música para ritual masónico compuesta por Ramón Figueroa Morales (Santiago de Cuba, 1863-1928) fue localizada en el archivo de música de la Catedral de Santiago de Cuba (AMCSC). La mencionada catedral, fundada en 1522, fue un espacio propicio para la práctica musical a lo largo de todo el período colonial, lo cual favoreció la conformación de un archivo que constituye el más antiguo y exuberante reservorio de música religiosa para el culto cristiano en Cuba. Por la importancia eclesiástica que tuvo esta sede para el resto del archipiélago, contaba con capilla de música conformada por ministriles y cantores bajo la dirección de notables maestros de capilla, dentro de los que se pueden referenciar a Esteban Salas, Juan Paris y Cratilio Guerra ${ }^{15}$.

Al referirse a esta institución musical, la historiadora Olga Portuondo expresó que "[...] contribuyó a la afirmación de una identidad propia [...] para la forja de un patrimonio artístico pleno de motivos, melodías y ritmos [...] que permite explicar la rica herencia musical cubana" $"$. Dentro de las más de 670 partituras que se atesoran en el archivo de música de Catedral de Santiago de Cuba, y como parte de las acciones de catalogación de sus fondos documentales llevadas a cabo por un grupo de especialistas entre 1999 y 2016, se localizaron siete obras compuestas íntegramente por Ramón Figueroa Morales y cuatro arreglos musicales realizados por éste a obras de otros compositores. No es gratuito que estas partituras se atesoren en la mencionada institución, si se tiene en cuenta que este compositor compuso obras musicales para ser interpretadas durante la liturgia católica por los integrantes de la mencionada capilla de música, de las cuales se conserva su Misa para dos voces y órgano.

Entre sus manuscritos autógrafos y signados se identificó la Música para ritual masónico como de interés patrimonial por poseer un significativo valor documental, en tanto es testimonio de la práctica musical dentro de la liturgia masónica en Cuba. En ese mismo sentido, estas partituras poseen relevante valor histórico y cultural dado que son resultados de un ejercicio musical casi desconocido en el país. Esta música en su conjunto posee un valor simbólico sin igual, constituyendo la representación material de un entramado de pensamiento moral que condiciona sus características estéticofuncionales. Dada sus particularidades, la Música para ritual masónico de Ramón Figueroa Morales es un objeto de estudio que no posee parangón en las historias culturales de la música cubana, siendo así pertinente realizar un proceso de gestión que contribuya a su rescate como bien integrante del patrimonio histórico-documental de la música. La localización de dichos documentos dentro de un archivo catedralicio corrobora que la música atesorada en estas instituciones no es exclusivamente religiosa.

\footnotetext{
${ }^{15}$ Miriam Escudero, Músicos de la Catedral de Santiago de Cuba, siglos XVI-XIX (Santiago de Cuba: Ediciones Caserón, 2012).

${ }^{16}$ Escudero, Músicos de la Catedral de Santiago de Cuba, 29.
} 
Durante los trabajos de rastreo de los bienes culturales pueden hallarse referencias a instituciones de diferente índole que deben ser verificadas, de ahí la importancia y transversalidad de las labores preliminares de estudio. La identificación de la Música para ritual masónico dentro de un corpus musical heterogéneo ha permitido aunar y encaminar los recursos humanos y materiales para llevar a feliz término cada una de las acciones de gestión propuestas.

Imagen 3

Ramón Figueroa Morales

Para Iniciación, Primer Viaje, Segundo Viaje, Tercer y Último Viaje, Contrabajo

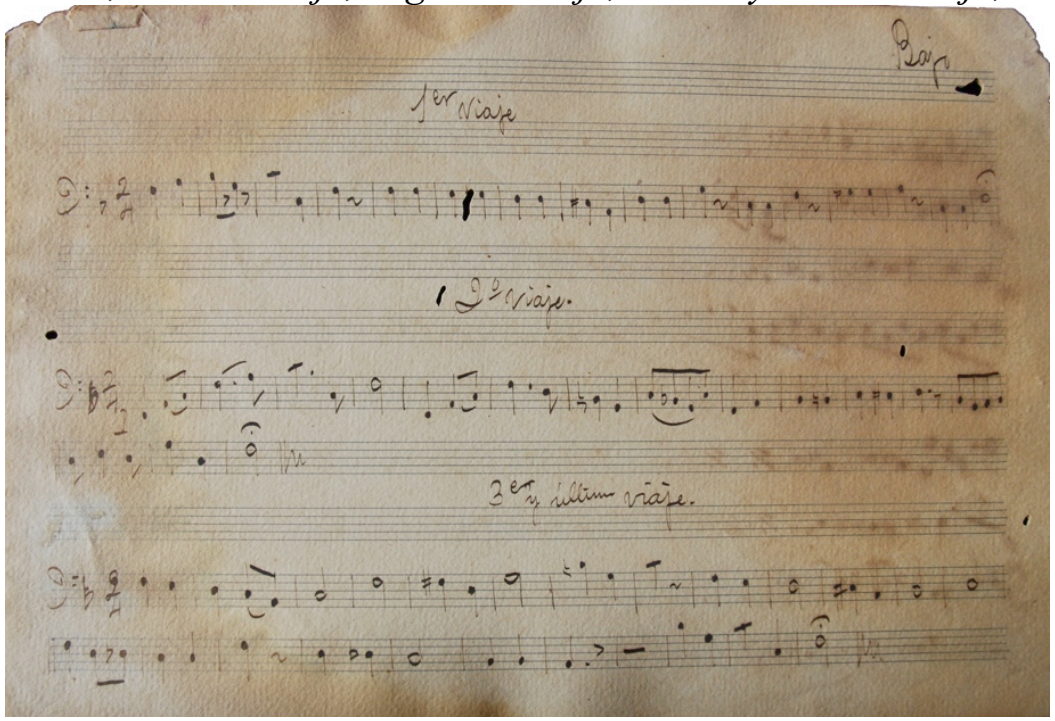

Fuente: Fotografía del facsimilar, AMCSC, Leg.28, Exp.05.

\section{Inventario y catalogación}

La confección del inventario de las obras musicales de Ramón Figueroa Morales localizadas en el archivo de música de la Catedral de Santiago de Cuba (ver cuadro 1), tuvo como objetivos la organización y descripción mínima de los bienes documentales mencionados, como forma ineludible de conocer y proteger lo atesorado. Por lo que se determinó que este instrumento de gestión debía contener información sintética de carácter contable, solo la necesaria, estableciéndose los siguientes campos descriptivos:

- SIGNATURA MODERNA: Localización y referencia de la obra catalogada dentro del archivo de música de la Catedral de Santiago de Cuba: número de legajo (Leg.) y de expediente (Exp.) dentro del legajo.

- TÍTULO UNIFORME: Título normalizado de la obra musical según criterios resultantes de la investigación documental, el cual no tiene por qué coincidir con el refrendado en la partitura.

- RELACIÓN ABREVIADA DE INSTRUMENTOS: Relación abreviada de voces e instrumentos consignados en la obra musical. 
- OBSERVACIONES DE LA FUENTE: Tipología de la partitura (manuscrita o impresa), si se encuentra fechada o signada, tempo de la obra musical, autoría de los textos, dedicatorias y otros datos que no se describen en ningún otro campo.

\section{Cuadro 1}

Inventario de las obras y arreglos musicales realizados por Ramón Figueroa Morales localizados en el archivo de música de la Catedral de Santiago de Cuba

\begin{tabular}{|c|c|c|c|}
\hline $\begin{array}{c}\text { SIGNATURA } \\
\text { MODERNA }\end{array}$ & $\begin{array}{c}\text { TÍTULO } \\
\text { UNIFORME }\end{array}$ & $\begin{array}{c}\text { RELACIÓN } \\
\text { ABREVIADA DE } \\
\text { INSTRUMENTOS }\end{array}$ & OBSERVACIONES DE LA FUENTE \\
\hline Leg. 23, Exp. 22 & $\begin{array}{l}\text { Misa a dos } \\
\text { voces y } \\
\text { órgano }\end{array}$ & 2 voces y órgano & $\begin{array}{l}\text { Partitura manuscrita / [En portada:] Regalada } \\
\text { al Padre Junquera / [En portada:] Copia / [En } \\
\text { portada:] cuño en gomígrafo de F. Barthelemy } \\
\text { Flores, Copista de Música, Santiago de Cuba / } \\
\text { [Partes:] Kyrie, Gloria, Credo, Sanctus, } \\
\text { Benedictus y Agnus Dei }\end{array}$ \\
\hline Leg. 28, Exp. 05 & $\begin{array}{l}\text { Música para } \\
\text { ritual } \\
\text { masónico }\end{array}$ & $\begin{array}{l}\text { Fl, Ob, ClI, Fg o Fi, } \\
\text { Crn, TbnI/II, VnI, } \\
\text { VnII, Vc, Cb }\end{array}$ & $\begin{array}{l}\text { Partitura manuscrita / Fechada: mayo de } 1916 \\
\text { y julio de } 1918 \text { / Signada / [Partes:] Himno } \\
\text { Nacional Masónico, Romanza El Juramento, } \\
\text { Para Iniciación, Marcha Fúnebre Acacia y } \\
\text { Melody / Melody in F es un arreglo sobre } \\
\text { música original de Antón Rubinstein }\end{array}$ \\
\hline Leg. 28, Exp. 12 & $\begin{array}{l}\text { Himno } \\
\text { Heredia }\end{array}$ & $\begin{array}{l}\text { Voz, Fl, ClI, ClII, } \\
\text { Crn, TbnI, TbnII, } \\
\text { Bd o Fg, VnI, VnII, } \\
\text { Vla, Vc, Cb, Pn }\end{array}$ & $\begin{array}{l}\text { Partitura manuscrita / Fechada: } 1903 \text { / Signada } \\
\text { / Tempo Marcial poco lento / Letra de } \\
\text { Desiderio Fajardo Ortiz / Dedicado al poeta } \\
\text { José María Heredia / [En primer folio del } \\
\text { arreglo para canto y piano:] cuño en } \\
\text { gomígrafo de María Luisa Bory, Prof. de } \\
\text { Música E.N.K.O, Santiago de Cuba }\end{array}$ \\
\hline Leg. 28, Exp. 15 & La Bayamesa & Pn & $\begin{array}{l}\text { Partitura manuscrita / Fechada: } 1925 \text { / Signada } \\
\text { / Tempo Lento / Arreglo sobre música original } \\
\text { de Castillo y Fornaris / [Filigranas:] José } \\
\text { Vilaseca }\end{array}$ \\
\hline Leg. 28, Exp. 38 & $\begin{array}{l}\text { Himno } \\
\text { Guerrero }\end{array}$ & $\begin{array}{l}\text { Fl, Ob, ClI, ClII, } \\
\text { CrnI/II, Bd, VnI, } \\
\text { VnII, Vla, Vc, Cb }\end{array}$ & $\begin{array}{l}\text { Partitura manuscrita / Fechada: } 1896 \text { / Signada } \\
\text { / Tempo Marcial / Dedicado al general } \\
\text { Antonio Maceo / [Filigranas:] José Guarro }\end{array}$ \\
\hline Leg. 28, Exp. 39 & $\begin{array}{l}\text { Himno } \\
\text { Escolar a } \\
\text { Martí }\end{array}$ & $\begin{array}{l}\text { Fl, Ob, ClI, TbnII, } \\
\text { Bd, Crn, VnI, VnII, } \\
\text { Vc, Cb, }\end{array}$ & $\begin{array}{l}\text { Partitura manuscrita / Fechada: mayo de } 1914 \\
\text { / Signada / Tempo Maestoso / Letra de } \\
\text { Joaquín Navarro Riera (Ducazcal) / Dedicado } \\
\text { al apóstol José Martí }\end{array}$ \\
\hline Leg. 28, Exp. 40 & $\begin{array}{l}\text { Himno } \\
\text { Patriótico } 20 \\
\text { de Mayo }\end{array}$ & $\begin{array}{l}\text { Coro de niños, Fl, } \\
\text { Ob, ClI, ClII, } \\
\text { CrnI/II, TbnI/II, } \\
\text { TbnIII, Bd, VnI, } \\
\text { VnII, Vc, Cb, }\end{array}$ & $\begin{array}{l}\text { Partitura manuscrita / Fechada: abril de } 1913 \text { / } \\
\text { Signada / Dedicado al general Menocal, } \\
\text { presidente de la República / [En portada:] } \\
\text { Copista, F. Barthelemy Flores / [En particella } \\
\text { de niños:] orquesta un tono bajo }\end{array}$ \\
\hline Leg. 28, Exp. 41 & $\begin{array}{l}\text { Himno } \\
\text { Escolar "Luz y } \\
\text { Caballero" }\end{array}$ & $\begin{array}{l}\text { Fl, ClI, ClII, TbnI, } \\
\text { TbnII, Crn, VnI, } \\
\text { VnII, Cb }\end{array}$ & $\begin{array}{l}\text { Partitura manuscrita / Fechada: enero de } 1914 \\
\text { / Tempo Solemne / Arreglo sobre música } \\
\text { original de Guillermo Tomás / Letra de Oscar } \\
\text { Ugarte / [Filigranas:] U. Almirall B }{ }^{\mathrm{A}}\end{array}$ \\
\hline Leg. 28, Exp. 56 & $\begin{array}{c}\text { Himno } \\
\text { Austriaco }\end{array}$ & $\mathrm{Bd}, \mathrm{Tbn}$ & $\begin{array}{l}\text { Partitura manuscrita / Fragmentos de papel de } \\
\text { dos pentagramas cada uno / [Filigranas:] K. S. } \\
\text { \& Co. IMPERIAL }\end{array}$ \\
\hline
\end{tabular}

Elaboración propia. 
Específicamente para la elaboración de la ficha catalográfica de la Música para ritual masónico (ver cuadro 2), no solo se tuvieron en cuenta los campos descriptivos del inventario, sino que se incluyeron otros campos resultantes de la adecuación de la Norma de Catalogación del Repertorio Internacional de las Fuentes Musicales (RISM) España, serie A/II - Manuscritos musicales desde $1600^{17}$, atendiendo al contexto musical cubano de principios del siglo XX y a las propias particularidades del objeto de estudio. Dicha norma ha sido ampliamente utilizada para la descripción de otros documentos de música anotada pertenecientes al archivo de música de la Catedral de Santiago de $\mathrm{Cuba}^{18}$ y a las danzas del compositor estudiado contenidas en el libro "Música de salón. Santiago de Cuba, siglo XIX. Danzas para piano""19. En este particular, para la conformación del catálogo del autor se adicionaron los siguientes campos descriptivos:

- NOMBRE NORMALIZADO DEL COMPOSITOR: Nombre reconstruido del autor de la obra catalogada, incluyendo fechas de nacimiento y muerte.

- OTROS NOMBRES: Otros nombres referenciados en la fuente documental que no se hayan incluidos en otros campos.

- AUTÓGRAFO: Si la obra catalogada es autógrafa se indicará con "a".

- COLECCIÓN CONTENIDO: Total de obras simples que integran la obra catalogada.

- COLECCIÓN OBRAS: Títulos de las obras simples que integran la obra catalogada.

- DATACIÓN MANUSCRITO: Fecha de la copia que no siempre coincide con la fecha de composición.

- NÚMERO DE PARTES: Número de partes instrumentales con que cuenta la obra catalogada, en el sentido de material físico.

- TONALIDAD DE LAS OBRAS: Tonalidades manifiestas de cada una de las obras simples que integran la obra catalogada, utilizando las abreviaturas descritas en el anexo 3.

- RELACIÓN INSTRUMENTOS PARTES: Relación abreviada de instrumentos consignados en cada una de las obras simples que integran la obra catalogada, utilizando las abreviaturas descritas en el anexo 3.

- MATERIAL QUE FALTA: Indicación del material musical que falta.

- MEDIDAS: Ofrecidas en centímetros, altura x anchura.

- FILIGRANAS: Referencia a marcas de aguas de los productores de papel.

\footnotetext{
${ }^{17}$ José Vicente González Valle et al (trads.). Normas Internacionales para la Catalogación de Fuentes Musicales Históricas (Serie A/II, Manuscritos musicales, 1600-1850) (Madrid: Repertorio Internacional de Fuentes Musicales RISM-España, 1996).

${ }^{18}$ Ejemplo de ello son los libros Miriam Escudero. Esteban Salas, maestro de capilla de la Catedral de Santiago de Cuba (1764-1803). Libro VIII (La Habana: Ediciones Boloña, 2011); Claudia Fallarero. Juan Paris, maestro de capilla de la Catedral de Santiago de Cuba (1805-1845). Villancicos de Navidad. Libro I (La Habana: Ediciones Cidmuc, 2011); y Franchesca Perdigón. Cratilio Guerra Sardá (Santiago de Cuba, 1835-1896). Repertorio religioso (La Habana: Ediciones Cidmuc, 2012).

${ }^{19}$ Franchesca Perdigón. Música de salón. Santiago de Cuba, siglo XIX. Danzas para piano (Colección Patrimonio Musical Cubano siglo XIX. La Habana: Ediciones Cidmuc, 2015).
} 
- INCIPIT MUSICAL: Primeros compases musicales del instrumento melódico más agudo tomado diplomáticamente.

- ESTRENO: Lugar y fecha de la primera ejecución de la obra, si aparece o se conoce.

- BIBLIOGRAFÍA: Referencia bibliográfica sobre la obra o colección catalogada.

La realización de las precedentes acciones de inventario y catalogación implicaron la búsqueda de fuentes secundarias de información que tributaran a la descripción del objeto de estudio, poniendo en valor la transversalidad del análisis documental. La catalogación de la Música para ritual masónico constituyó un paso inicial para validar la ficha utilizada, en aras de recomendar su uso para documentos similares. En la confección de los íncipits musicales se manejaron fragmentos de las partituras resultantes de las acciones de transcripción digital. Estos aspectos dan cuenta de la relación sistémica que debe existir entre cada una de las acciones propuestas para su salvaguarda. Sus resultados tributan a una mejor gestión del bien integrante del patrimonio histórico-documental de la música, logrando recuperar la información que le concierne mediante instrumentos que permitan su control y protección.

Imagen 4

Ramón Figueroa Morales.

Para Iniciación, Primer Viaje, Segundo Viaje, Tercer y Último Viaje, Trombones Iy II

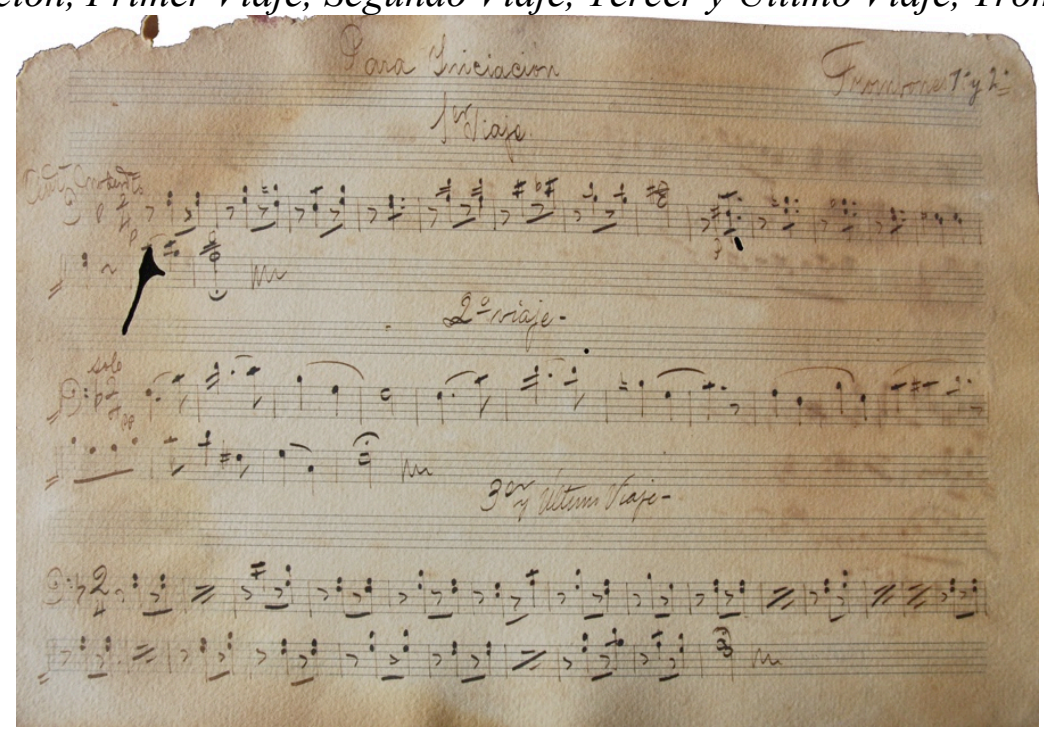

Fuente: Fotografía del facsimilar, AMCSC, Leg.28, Exp.05. 


\section{Cuadro 2}

Ficha catalográfica de la Música para ritual masónico de Ramón Figueroa Morales

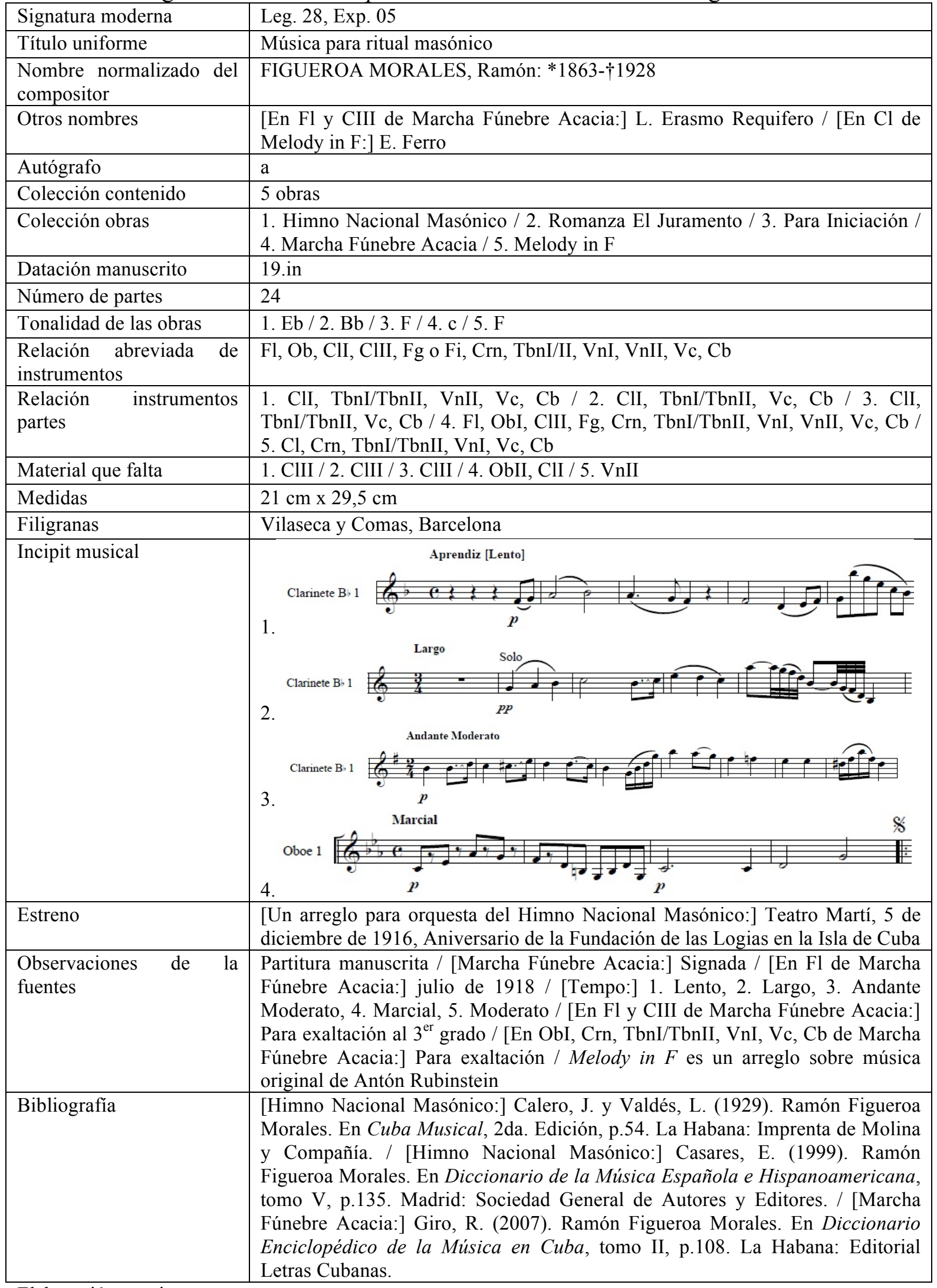

Elaboración propia. 


\section{Digitalización}

Para la digitalización de la Música para ritual masónico compuesta por Ramón Figueroa Morales se utilizó una cámara fotográfica marca NIKON, modelo D80. Se configuró el punto focal de la cámara en 7.1, el tiempo de exposición en 1/30 s, velocidad ISO-400, compensación de exposición 0 paso, distancia focal $24 \mathrm{~mm}$, con una apertura máxima de 3.8, sin flash obligatorio y una longitud focal de $35 \mathrm{~mm}$ para lograr óptimas imágenes que permitieran una posterior transcripción de las obras (Ver Ilustraciones). La configuración descrita permitió obtener fotografías digitales con 300 píxeles de resolución, 24 bits de profundidad, 2 de unidad de resolución, 4 bits comprimidos/píxel y con sRGB para la representación del color. A nivel visual, estas características se evidencian en el logro de imágenes con parámetros normales de contraste y saturación, baja nitidez y un balance automático de blanco. El formato utilizado para la producción de las imágenes digitales fue el JPG, mientras que el empleado para presentarlas en este trabajo fue el PDF.

Posteriormente, para la transcripción del documento musical su utilizó el software FINALE 2012a de MakeMusic Inc. En esta traslación se recurrió a criterios textuales que permiten una mejor lectura de las obras gestionadas ${ }^{20}$. Una vez transcrita, se condujo a la realización de una edición crítica de la Música para ritual masónico; en la que se cambió el clarinete en Do y el cornetín por clarinete y trompeta en Sib respectivamente, dado que los primeros de estos instrumentos musicales se encuentran actualmente en desuso. Asimismo, se normalizaron articulaciones, fraseos y dinámicas en aquellas partes en que no aparecían referenciadas, propiciando una interpretación coherente de las obras; y se realizaron algunos cambios de notas sin que fuera afectada la armonía original.

\footnotetext{
${ }^{20}$ James Grier, La edición crítica de la música: historia, método y práctica (Madrid: Ediciones AKAL,
} 2008). 


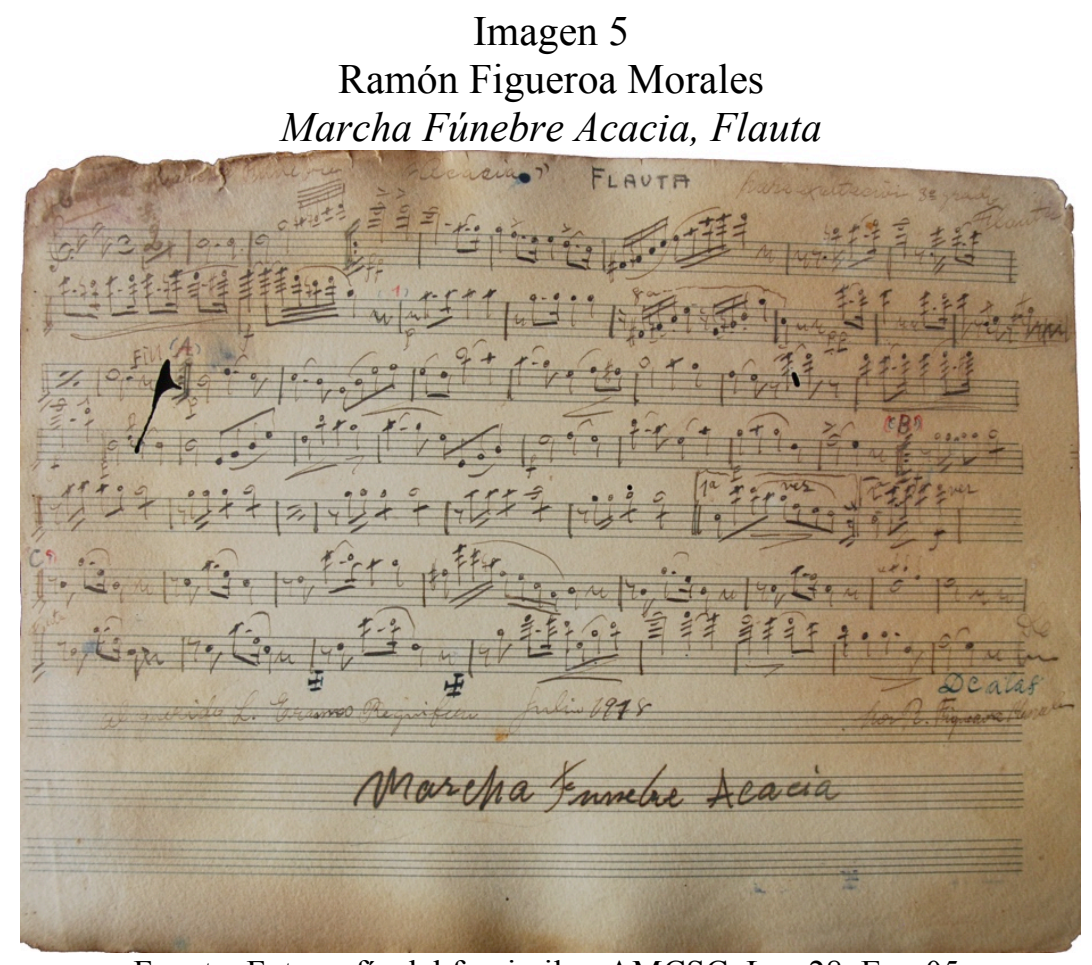

Fuente: Fotografía del facsimilar, AMCSC, Leg.28, Exp.05.

\section{Estudio biográfico de Ramón Figueroa Morales (1863-1928)}

Ramón Figueroa Morales nació el 14 de septiembre de 1863 en Santiago de Cuba, ciudad más importante de la antigua Provincia de Oriente y actual cabecera provincial de la provincia homónima ${ }^{21}$. Proveniente de una familia "parda" de tradición musical, su padre, Manuel Figueroa, fue un reconocido director de orquesta de baile en la década del 50` del siglo XIX y su hermano, Antonio Figueroa Morales (1852-1892), destacó como violinista de la capilla de música de la catedral santiaguera y como profesor de música en el Seminario San Basilio El Magno de la misma urbe ${ }^{22}$. De ambos familiares Ramón Figueroa obtuvo los primeros rudimentos musicales, formación profesional que se concretó a partir de 1875, cuando ganó el ejercicio de oposición a violín concertino de la capilla de música donde su hermano había sido violinista $^{23}$. A partir de 1882 comenzó a desarrollar una sostenida labor como concertista, tanto en el ámbito eclesiástico como en los salones y tertulias de la época, llegando a formar parte del Salón Haydn, veladas musicales que organizaba Rodolfo Hernández Soleliac (1856-1937) en la casa del cónsul alemán Germán Michaelson ${ }^{24}$.

\footnotetext{
${ }^{21}$ Radamés Giro Almenares, Diccionario Enciclopédico de la Música en Cuba, tomo II (La Habana: Editorial Letras Cubanas, 2007).

${ }^{22}$ Helio Orovio, en Emilio Casares Rodicio ed., Diccionario de la Música Española e Hispanoamericana, tomo V (Madrid: Sociedad General de Autores y Editores, 1999), 135.

${ }^{23}$ Giro Almenares, Diccionario Enciclopédico, 108.

${ }^{24}$ Perdigón, Música de salón, 31.
} 
En 1895, empezada la Guerra Necesaria, se trasladó a Santo Domingo, República Dominicana, donde conoció personalmente al general Antonio $\mathrm{Maceo}^{25}$ y se hizo miembro del Partido Revolucionario Cubano ${ }^{26}$. Acompañado por el compositor Rodolfo Hernández Soleliac y los músicos catedralicios Tomás Planes y Fermín Mirabal, gestaron una serie de conciertos en esa ciudad foránea y otras urbes de Haití, Jamaica y Puerto Rico, con el objetivo de recaudar fondos para la causa independentista $^{27}$. En 1899, posterior a su regreso a la Isla, Ramón Figueroa Morales cooperó en la fundación y auge de la Academia de Bellas Artes de Santiago de Cuba junto a Emilio Bacardí y José Joaquín Tejada, institución en la que se desempeñó como profesor de violín y director de la Sección de Música ${ }^{28}$. El 5 de diciembre de 1916 figuraba como director de la Columna Armónica de la Logia Prudencia No.2 de Santiago de Cuba durante el estreno de la versión orquestal de su Himno Nacional Masónico $^{29}$, por lo que debió haberse iniciado en la masonería antes de esa fecha. Desde la fundación del Conservatorio Provincial de Música de Oriente por Dulce María Serret en 1927, y hasta su deceso el 4 de mayo de 1928, Ramón Figueroa Morales fue subdirector de este ${ }^{30}$. Este músico compuso repertorio religioso y profano, y entre sus obras se conservan: una misa, himnos, marchas, danzas para piano, obras para violín y piano, y danzones para orquesta, siendo considerado por algunos especialistas como un "renovador de la danza cubana" 31 .

Su quehacer como profesor y compositor sirvió de catalizador del pensamiento y desarrollo musical de su época, dejando un legado que ha llegado hasta las generaciones actuales $^{32}$. Portador del bagaje musical adquirido en el seno de su familia y en otros espacios de su ciudad ${ }^{33}$, la música para violín y piano de Ramón Figueroa Morales está influenciada por la creación europea del siglo XIX que llegó a Cuba mediante el repertorio interpretado por concertistas y profesores provenientes del Viejo Continente que ofrecieron recitales en diferentes ciudades o se radicaron en el país ${ }^{34}$. El contexto musical de su época estuvo marcado por la permanencia de gustos estéticos de la segunda mitad del siglo XIX: se bailaban danzones y danzas, cantaban habaneras y ponían en escena zarzuelas y sainetes que exaltaban la vida nacional y el patriotismo por las luchas independentistas. A pesar de fundada la República en 1902, seguía sin

${ }^{25}$ Antonio Maceo (Santiago de Cuba, 1845- Punta Brava, 1896), general cubano que participó en la Guerra de los Diez Años y en la Guerra Necesaria, donde llegó a ser el segundo jefe militar del Ejército Libertador. En Eduardo Torres-Cuevas y Oscar Loyola Vega, Historia de Cuba 1492-1898. Formación y liberación de la nación (La Habana: Editorial Pueblo y Educación, 2002).

${ }^{26}$ Giro Almenares, Diccionario Enciclopédico, 108.

${ }^{27}$ Perdigón, Música de salón, 31.

${ }^{28}$ José Calero Martín y Leopoldo Valdés Quesada, Cuba Musical (La Habana: Imprenta de Molina y Compañía, 1929), 54.

${ }^{29}$ Ramón Figueroa Morales, Himno Nacional Masónico (La Habana: Biblioteca-Archivo Odilio Urfé del Museo Nacional de la Música), partitura manuscrita 4-5888.

${ }^{30}$ Calero Martín y Valdés Quesada, Cuba Musical, 54.

${ }^{31}$ Helio Orovio, Diccionario de la música cubana. Biográfico y técnico (La Habana: Editorial Letras Cubanas, 1992), 174.

${ }^{32}$ Giro Almenares, Diccionario Enciclopédico, 108.

${ }_{33}^{33}$ Perdigón, Música de salón.

${ }^{34}$ Giro Almenares, Diccionario Enciclopédico, 108. 
reconocerse la contribución tímbrica y rítmica de la población negra a la sonoridad de la música cubana, aunque ese aporte estuviera oculto en el sentir cotidiano ${ }^{35}$.

Igualmente, las prácticas musicales se diferenciaban atendiendo a sus usos, funciones y contextos socioculturales donde germinaban. Por ello es que de esa época aún pervive música proveniente del entorno rural donde se aprendía por tradición oral; también música del ambiente urbano que comenzó a editarse a principios del siglo XIX y se vendía generalmente en separatas o como regalos a las suscriptoras de revistas; así como música para públicos de mayores niveles adquisitivos que acudían tanto a la iglesia como a las veladas de los salones de las familias de rango social y los teatros elegantes $^{36}$. Es importante señalar que los músicos de las orquestas de la época participaban lo mismo en fiestas elegantes, festejos oficiales, solemnidades de la iglesia, acompañamiento musical de óperas o zarzuelas ${ }^{37}$, y - bajo estas nuevas evidenciastambién en la columna armónica de una logia masónica. Ello se debe a la constante búsqueda de ingresos monetarios que les permitiera una subsistencia decorosa junto a sus familias, en un país que se abría al siglo $\mathrm{XX}$ con bases económicas y relaciones políticas decimonónicas heredadas del colonialismo español.

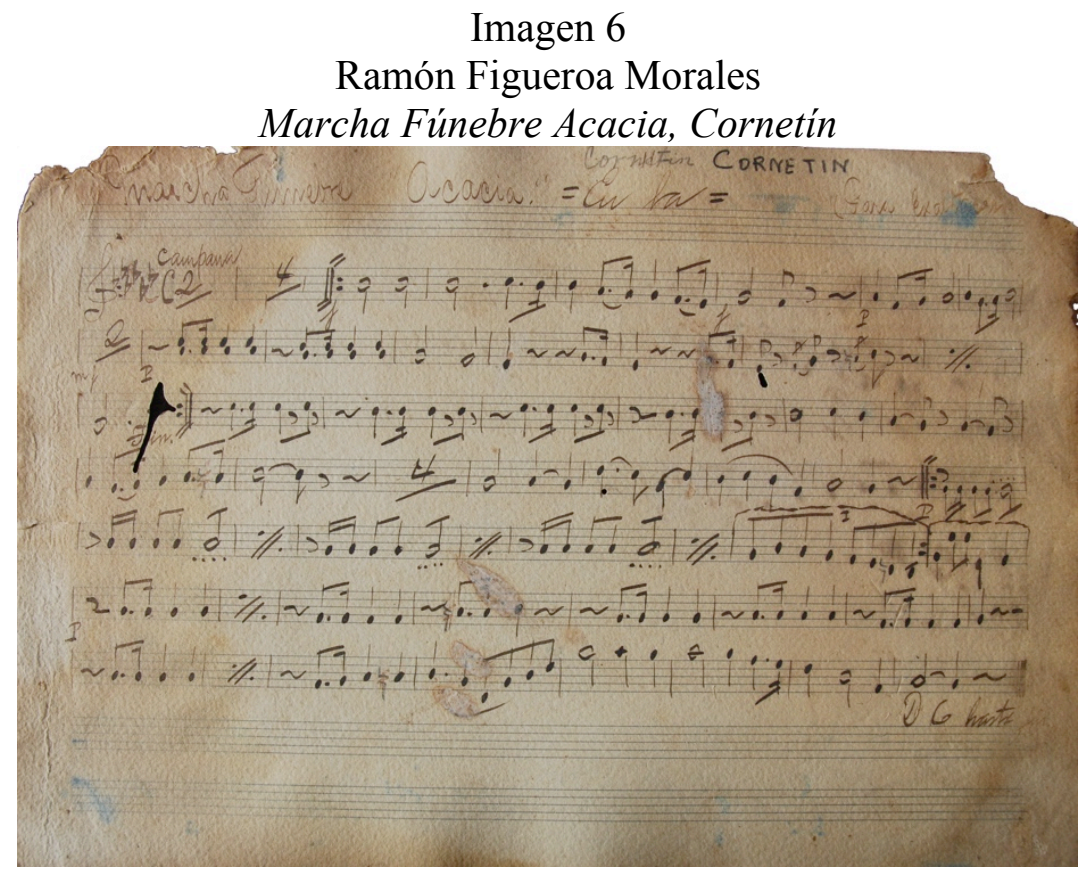

Fuente: Fotografía del facsimilar, AMCSC, Leg.28, Exp.05.

\footnotetext{
35 Zoila Lapique Becali, "La República: el gran despertar sonoro", Debates Americanos 12 (enerodiciembre 2002): 175-182.

${ }^{36}$ María Teresa Linares, "La música. Reafirmación de lo cubano", Debates Americanos 12 (enerodiciembre 2002): 165-174.

${ }^{37}$ Margarita Pearce. "La actividad musical en los espacios religiosos de La Habana en la segunda mitad del siglo XIX" (Tesis de maestría interuniversitaria en patrimonio musical, Universidad de Oviedo, 2016).
} 


\section{Análisis músico-funcional de la Música para ritual masónico}

Como se puede constatar en la "Liturgia Masónica Aprendiz" arreglada y anotada por Francisco Rodríguez en 1901, maestro de la logia habanera "Hijos de la Viuda", el trabajo masónico se divide en tres grandes partes: la apertura de la logia, la iniciación y la clausura de la logia ${ }^{38}$. A su vez, la iniciación se divide en dos sub-partes delimitadas por un recésit o receso: la primera concluye con el juramento del iniciado como masón y la segunda consuma un precepto. Durante una tenida regular en Santiago de Cuba, a principios del siglo XX - como la estudiada, que concierne al grado de Aprendiz del Rito Escocés Antiguo y Aceptado- aparecen un total de ocho referencias expresas a la práctica musical: una en la apertura, seis en la iniciación y una en la clausura. Desde el punto de vista de la retórica musical, estas referencias aluden al pathos o sentimientos que debe comunicar la música interpretada en ese momento o al tempo de su ejecución, y no a repertorios explícitos. Ejemplo de ello son "música pausada" para invocar al Gran Arquitecto del Universo G.A.D.U., "la música tocará despacio en cada viaje" aludiendo al tempo del repertorio que debe acompañar los tres desplazamientos que hará el iniciado durante el ritual, y "música solemne y pausada" como acompañamiento del juramento ${ }^{39}$. Con sintagmas como "Se toca algo adecuado en el órgano" y "Tócase algo solemne en el órgano" instrumento que debe haber acompañado musicalmente a la liturgia masónica en Cuba, hecho que ya se había producido en Europa durante la primera mitad del siglo XIX.

Sin embargo, hasta el momento no se ha encontrado repertorio alguno que dé cuenta de la existencia real de dichos instrumentos musicales en alguna logia masónica cubana, dejando abierta una línea de trabajo para próximas investigaciones. Pero sin dudas, de lo mencionado anteriormente y de los siguientes resultados del análisis realizado a la Música para ritual masónico, es posible lucubrar que el Himno Nacional Masónico fuera utilizado para la apertura o clausura de la logia. Las tres secciones de la obra Para Iniciación se corresponden con cada uno de los viajes realizados durante la primera parte del rito (ver imágenes 3 y 4), y El Juramento se emplea en el momento homónimo dentro de la liturgia. En las partes instrumentales de la pieza Acacia se refrenda que fue utilizada para la exaltación del $3^{\text {er }}$ grado (ver esquina superior derecha de las imágnes 5 y 6), es decir, del grado de maestro masón, único de su tipo que necesitaría de una marcha fúnebre que apoye sonoramente la muerte simbólica del Compañero para renacer como Maestro de la doctrina masónica.

Teniendo en cuenta algunos de los parámetros para el análisis musical recomendados por Margarita Lorenzo y Arantza Lorenzo en el libro "Análisis Musical. Claves para entender e interpretar la música"41, el Himno Nacional Masónico, Para Iniciación, El Juramento y Acacia poseen forma ternaria simple, estructura común en

\footnotetext{
${ }^{38}$ Francisco Rodríguez, Liturgia Masónica Aprendiz (La Habana: Imprenta Avisador Comercial, 1901).

${ }^{39}$ Rodríguez, Liturgia Masónica Aprendiz, 18-21.

${ }^{40}$ Rodríguez, Liturgia Masónica Aprendiz, 14-15.

${ }^{41}$ Margarita Lorenzo y Arantza Lorenzo., Análisis Musical. Claves para entender e interpretar la música (Barcelona: Editorial de Música Boileau, 2004).
} 
los repertorios relacionados con la masonería. Las dos primeras de esas obras están conformadas por tres secciones diferentes $(a-b-c)$ que rompen con el esquema tradicional de que las primeras y terceras secciones deben ser similares (a-b-a), como sí lo son en Acacia. En El Juramento las tres secciones guardan identidad temática y tonal entre sí mediante una forma musical continua (a-a $\left.{ }^{`}-a^{\prime \prime}\right)$, reafirmando su carácter propositivo y, por tanto, dando la sensación de ratificación sonora. Las melodías de las obras que integran la Música para ritual masónico coinciden en que son tonales con predominio de los grados I y V, en las cuales aparecen relaciones cadenciales explícitas y modulaciones diatónicas intratonales. En estas obras predomina la textura homofónica con movimientos paralelos ocasionales en varios instrumentos. La línea melódica es conducida por el clarinete en el Himno Nacional Masónico, Para Iniciación y El Juramento, y por la flauta, oboe y clarinete en Acacia. Ellas presentan un perfil melódico predominantemente mixto, alternando movimientos interválicos conjuntos y disjuntos, lo cual enriquece el resultado sonoro. Estos aspectos melódicos, desgajados de complejidad, proporcionan coherencia al discurso musical propio de cada una de las obras analizadas y coadyuvan a que sean fácilmente asimilados por los participantes del ritual.

Desde el punto de vista rítmico y métrico, el Himno Nacional Masónico y Acacia están escritas en compases cuaternarios (de compasillo), mientras que Para Iniciación en un compás binario (2/4) y El Juramento en un compás ternario (3/4). Los comienzos de las tres últimas obras son téticos mientras que el del Himno Nacional Masónico es anacrúsico, pero los cuatro finales son masculinos. De este himno es importante destacar las llamadas de atención del clarinete en el compás 8 y del clarinete y los trombones en el compás 16, tópico de caza que anuncia - en este caso- la entrada y salida a la logia de los compañeros y los maestros respectivamente. Las obras que conforman la Música para ritual masónico son predominantemente homorrítmicas, dado que el ritmo es idéntico o muy semejante en todos los instrumentos, e isométricas, puesto que fueron compuestas bajo patrones métricos uniformes, adquiriendo un carácter más homogéneo y acorde con la mayor parte de la música occidental comprendida entre los siglos XVI y XIX. Ello provoca que la textura rítmico-métrica sea percibida de forma monorrítmica horizontal y verticalmente, manteniéndose un patrón constante de acentuación que facilita el carácter traslaticio de obras como el Himno Nacional Masónico y Para Iniciación.

En las cuatro obras prima el uso de tríadas perfectas mayores y menores en su estado fundamental y sus inversiones, con duplicaciones múltiples que rebasan los planos de la armonía escolástica. Ello corrobora que Ramón Figueroa Morales comprendió que debía primar el desarrollo melódico de las partes sobre el armónico atendiendo a la funcionalidad litúrgica de las obras. En el Himno Nacional Masónico y Para Iniciación prima una disposición acordal abierta que imprime carácter de reposo a la música, mientras que en El Juramento y Acacia prevalecen las disposiciones acordales cerradas sonoramente y abigarradas, que contribuyen al carácter luctuoso que debe tener el momento que ocupan dentro del ritual. El Himno Nacional Masónico, 
Para Iniciación y Acacia están constituidas por frases cuadradas con semifrases y períodos binarios, aludiendo fraseológicamente a la perfección masónica que se encuentra en la cuadratura. Excepción de ello lo constituye El Juramento, cuya primera $\mathrm{y}$ tercera frase son ternarias y la segunda binaria, pero similares en cuanto a la organización rítmico-melódica. Dichas particularidades estructurales denotan el conocimiento que sobre la liturgia masónica tenía el compositor, quien tradujo a música algunas especificidades del simbolismo masónico. Ello coadyuvó a lograr el carácter necesitado en cada momento, aspecto que será tratado a cabalidad en una próxima publicación íntegra de los facsímiles musicales, con un análisis músico-funcional más profundo y la edición crítica de estas obras.

\section{Conclusión}

La aplicación del proceso de gestión a la Música para ritual masónico de Ramón Figueroa Morales sirvió para validar la propuesta metodológica empleada; bien conocida por investigadores musicales, pero pocas veces sistematizadas en casos concretos que contribuirían a verificar las acciones como formar de gestión de bienes integrantes del patrimonio histórico-documental de la música. Igualmente, ayudó a ampliar la noción que se tenía sobre las posibles instituciones donde se pueden localizar bienes documentales relacionados con la práctica musical y permitió la adecuación de una norma internacional para la confección de una ficha catalográfica que puede ser utilizada para describir documentos similares de música anotada. De ese modo, se contribuyó a una valoración positiva del uso de herramientas informáticas para la digitalización de partituras que forman parte integrante del patrimonio cultural no declarado de la Nación. Así, se ratificó que los resultados de cada una de las acciones propuestas pueden tributar a la difusión de los bienes gestionados, contribuyendo a que sean conocidos paulatinamente por diferentes públicos.

Teniendo en cuenta el contexto histórico, social y cultural de Santiago de Cuba en la transición entre los siglos XIX y XX, y las influencias estilísticas provenientes de las músicas decimonónicas europeas que pueden apreciarse en sus composiciones, es posible aseverar que Ramón Figueroa Morales constituyó un catalizador del pensamiento musical de su época. Las necesidades económicas imperantes en dicho período conjugado con un anhelo de cultivar la espiritualidad y moral individual, llevó a que varios músicos se integraran como Hermanos a las columnas armónicas masónicas. Algunos de ellos, como es el caso estudiado en el presente artículo, llegó a ser director del formato instrumental que sesionó en las tenidas de la Logia Prudencia No.2 de la ciudad mencionada; para la que compuso música expresa. Los resultados del análisis músico-funcional permitieron ubicar cada una de las obras integrantes de la Música para ritual masónico de Ramón Figueroa Morales en el posible lugar que ocuparan dentro de una tenida, desentrañando los elementos musicales morfosintácticos que coadyuvan a lograr el pathos necesitado en cada momento. 
Durante la implementación de la propuesta metodológica se demostró la validez y transversalidad de los estudios fundamentales y aplicados, hilo conductor del proceso de gestión. Ello reafirma la importancia que poseen las labores de investigación cuando se desea rescatar el patrimonio histórico-cultural de la música. En este particular, se contribuyó a la socialización de la práctica musical relacionada con la liturgia al interior de una logia masónica cubana, aspectos investigativos pocos abordados en la historiografía musical de la Mayor de las Antillas. De esa forma, se logró ampliar los horizontes sobre pesquisas en contextos histórico-culturales relegados a planos bajos de interés académicos, como puede ser el de la música masónica o paramasónica. Siendo este el primer acercamiento, con el tema propuesto se busca contribuir a la salvaguarda de tan importante expresión del patrimonio musical mediante una triangulación de algunos principios de la gestión documental, de la información y del conocimiento.

\section{Bibliografía}

Beresniak, Daniel. Los oficios y los oficiales de la logia. Bogotá: Ediciones Detrad, 2001.

Calero Martín, José y Leopoldo Valdés Quesada. Cuba Musical. La Habana: Imprenta de Molina y Compañía, 1929.

Casares Rodicio, Emilio ed. Diccionario de la Música Española e Hispanoamericana, tomo $V$. Madrid: Sociedad General de Autores y Editores, 1999.

Escudero, Miriam. Esteban Salas, maestro de capilla de la Catedral de Santiago de Cuba (1764-1803). Libro VIII. La Habana: Ediciones Boloña, 2011.

Escudero, Miriam. Músicos de la Catedral de Santiago de Cuba, siglos XVI-XIX. Santiago de Cuba: Ediciones Caserón, 2012.

Fallarero, Claudia. Juan Paris, maestro de capilla de la Catedral de Santiago de Cuba (1805-1845). Villancicos de Navidad. Libro I. La Habana: Ediciones Cidmuc, 2011.

Figueroa Morales, Ramón. Himno Nacional Masónico. La Habana: Biblioteca-Archivo Odilio Urfé del Museo Nacional de la Música, Partitura manuscrita 4-5888.

Figueroa Morales, Ramón. Música para ritual masónico. Santiago de Cuba: Archivo de Música de la Santa Basílica Metropolitana Iglesia Catedral, Legajo 28, Expediente 05.

Frau Abrines, Lorenzo. Diccionario Enciclopédico Abreviado de la Masonería. Buenos Aires: Editorial Kiev, 1962.

Giro Almenares, Radamés. Diccionario Enciclopédico de la Música en Cuba, tomo II. La Habana: Editorial Letras Cubanas, 2007.

González Valle, José Vicente trads. Normas Internacionales para la Catalogación de Fuentes Musicales Históricas (Serie A/II, Manuscritos musicales, 1600-1850). Madrid: Repertorio Internacional de Fuentes Musicales RISM-España, 1996.

Grier, James. La edición crítica de la música: historia, método y práctica. Madrid: Ediciones AKAL, 2008. 
J.D.R.Y. "Himno Masónico Universal".

(2005).

http://davidbenavente123.galeon.com/aficiones1388372.html

Lapique Becali, Zoila. "La República: el gran despertar sonoro". Debates Americanos 12 (enero-diciembre 2002): 175-182.

L.I.F. Algunas observaciones sobre la Columna de la Armonía. París: Gran Oriente de Francia, 2012.

Linares, María Teresa. "La música. Reafirmación de lo cubano". Debates Americanos 12 (enero-diciembre 2002): 165-174.

López Figaldo, Daniel. "Mozart y la Masonería. El gran arquitecto de la música". Filomúsica. Revista de música culta 41 (junio 2003). http://www.filomusica.com/filo41/mozart.html

López Maya, Juan de Dios. Columnas de Armonía. La tradición musical masónica del siglo XVIII y su reflejo en las logias venezolanas del siglo XIX. Caracas: s.e., 2012.

Lorenzo, Margarita y Lorenzo, Arantza. Análisis Musical. Claves para entender e interpretar la música. Barcelona: Editorial de Música Boileau, 2004.

Orovio, Helio. Diccionario de la música cubana. Biográfico y técnico. La Habana: Editorial Letras Cubanas, 1992.

Pearce, Margarita. "La actividad musical en los espacios religiosos de La Habana en la segunda mitad del siglo XIX". Tesis de Máster Interuniversitario en Patrimonio Musical, Universidad de Oviedo, 2016.

Perdigón, Franchesca. Cratilio Guerra Sardá (Santiago de Cuba, 1835-1896). Repertorio religioso. La Habana: Ediciones Cidmuc, 2012.

Perdigón, Franchesca. Música de salón. Santiago de Cuba, siglo XIX. Danzas para piano. Colección Patrimonio Musical Cubano siglo XIX. La Habana: Ediciones Cidmuc, 2015.

Rodríguez, Francisco. Liturgia Masónica Aprendiz. La Habana: Imprenta Avisador Comercial, 1901.

Sánchez Gálvez, Samuel. Legados perdurables de la masonería en Cienfuegos (18781902). Cienfuegos: Editorial Mecenas, 2010.

Suárez Marrero, Pablo Alejandro. "Propuesta metodológica para la gestión del patrimonio histórico-documental de la música en Cuba". Tesis de licenciatura en preservación y gestión del patrimonio histórico-cultural, Universidad de La Habana, 2016.

Torres-Cuevas, Eduardo. Historia de la masonería en Cuba. Seis ensayos. La Habana: Ediciones Imagen Contemporánea, 2013.

Torres-Cuevas, Eduardo y Oscar Loyola Vega. Historia de Cuba 1492-1898. Formación y liberación de la nación. La Habana: Editorial Pueblo y Educación, 2002. 